\title{
INTERNET OF THINGS - SURVEY ON RESEARCH CHALLENGES
}

\author{
PAVITHRA L*, REKHA D
}

School of Computer Science and Engineering, VIT Institute of Technology, Chennai, Tamil Nadu, India. Email: pavikotte@gmail.com

Received: 23 January 2017, Revised and Accepted: 03 March 2017

\begin{abstract}
Internet of things (IoTs) is a stage where consistently gadgets get to be more intelligent, consistently preparing gets to be savvy, and consistently correspondence gets to be educational. While the IoTs is as yet looking for its own particular shape, its belongings have as of now gazed in making mind-blowing strides as a widespread arrangement media for the associated situation. Engineering particular study does dependably clear the compliance of related field. The absence of general building information is in a matter of seconds standing up to the scientists to overcome the extent of IoTs driven methodologies. This writing overviews IoTs situated structures that are sufficiently able to enhance the comprehension of related apparatus, innovation, and approach to encourage engineer's necessities. Specifically or in a roundabout way, the displayed designs propose to take care of genuine issues by building also, organization of intense IoTs ideas. Encourage, explore challenges have been investigated to solidify the blank inside the present examples of plans to goad the scholastics additionally, wanders get included into searching for the possible course outs to appropriate the right constrain of IoTs. A principle commitment of this review paper is that it outlines the current best in class of IoTs designs in different spaces deliberately.
\end{abstract}

Keywords: Internet of things, Radio frequency identification, Security, Applications.

(C) 2017 The Authors. Published by Innovare Academic Sciences Pvt Ltd. This is an open access article under the CC BY license (http://creativecommons. org/licenses/by/4. 0/) DOI: http://dx.doi.org/10.22159/ajpcr.2017.v10s1.20513

\section{INTRODUCTION}

Over the traverse of the past connect of different decades; the network has been in a dependable condition to change. In begin the framework was portrayed by the World Wide Web, system to connected Hypertext Markup Language archives that lived on head of the Internet design. Connecting that design of standard Hyper Text Markup Language (HTML) pages well-ordered created in what precisely is implied as Web 2.0, in two-way managing persuaded the chance with reliable, than empowered customer collaboration, joint exertion and correspondence [1]. Web 2.0 headways join interpersonal cooperation organizations, sites, and wikis progressions that have been able to be fundamental to cutting edge social joint effort too with respect to general things. If the Web 2.0 right now overwhelms the internet, examiners has been worked toward next target, frequently insinuated as the semantic network and once in a while proposed as 3.0 [2]. The goal of the semantic network is to fabricate web word in a path that creates it sensible by objects, allowing objects, and seek after engines to hold up under on more acutely. Growing web word in organized affiliations could enter to the machines are handling and shared data in solitude, without to the necessity for people intervention [3].

Close to changes in the system movements, moves in sensor organizes and close to the Field Communication utilizing Radio Frequency Identifications marks had in addition been making. Joining of these two advances, i.e. the Network and Sensor Networks are inducing at advanced potential results with more innovations [4]. In likelihood to the design that could permit mastermind human -to-human correspondence finish the system as driven specialists to behold the interest of conveying more instruments on the web and grant to share in the internet as a staggering strategy of sufficient, self-overseeing contraptions [5]. This paper has made a perspective being proposed as the IoT.

If there are no broad definitions for the IoTs, the middle thought is normal things could be outfitted to the perceiving, searching, and frameworks organization are taking care of limits that can enter them to talk with each other besides then various contraptions in organizations over the network to achieved some supportive aim [6].
In inside thoughts fundamental the IoTs are not new. For an extensive timeframe, progresses, for instance, RFID, and sensor frameworks have been used as a piece of mechanical and creating settings for taking after tremendous ticket things, for example, cranes and creatures. Guide machine-to-machine correspondence is moreover no fresh if it is essential at the likelihood on the network in those customers, back end, and switches chat with both of the process [7]. The IoTs locations are change the utilization of presents advances in wording of the numeral and sorts of gadgets; moreover, the interconnection of systems of these devices over the network. For outline, most gadgets starting now on the internet were at first proposed to be a bit of the internet and have consolidated taking care of, stockpiling and framework limits [8].

These contraptions including to the server side, convenient PCs, notepad, and sharp mobile phones. What is the IoTs express is to join advancement to conventional contraptions, for instance, sound/video recipients, smoke discoverers, home mechanical assemblies, thus on and making them on the web, paying little respect to the likelihood that they were not at initially sketched out with this capacity as an essential concern [9]. One of the main things is transformative replace ensured at the IoTs are the blend of frameworks that contain these devices, making each contraption particularly open through the internet [10]. For example, RFID is using for an extensive time allotment to track things through particular parts of the stock system. Regardless, of the thing erase the rack of a merchant zone, the creator's opportunity to getting the test was missed [11].

Furthermore, a buyer was not capable get to the information of things they buying. If we give each thing a separate identity and preparing its information open through the network, the internet of things (IoTs) assurances to getting thing finding all through the whole thing process [12]. All the more commonly, the IoTs pause the certification to making an overall framework supporting unavoidable preparing and setting care among contraptions [13]. Inescapable handling and setting care are scratch necessities of encompassing learning, one of the key certifications of the IoTs. Encompassing knowledge would allow standard articles to get it their environment, coordinate with people and choose. 
A world overflowing with quick articles holds colossal certification for upgrading business systems and people's lives, in any case, it moreover goes with honest to goodness perils and concentrated particular situation that might be exhaust [14]. The aim of this survey is to outfit to the per client for a cognizance to the present state of IoTs, the progressions that encourage it, the utilizations of the IoTs, its challenging and late headways through a careful study and course of action of the written work [15].

\section{ARCHITECTURE}

Models are depended upon to address, make and diagram of the IoTs in a path that draws into the work sensibly. In express, the orbited, dissimilar features of the IoTs desire the usage to rigging/system, programing, also handle models arranged for aiding these gadgets, to the associations, and the works frames they would disturb. We drive gather arrange onto equipment/sort out, programing, set up also, general.

\section{Health care}

IoT-based design of smart hospital center is actualized to enhance viability of now hospital center data framework, for example, settled data point, rigid systems administration mode, furthermore related guideline. Mechanizing configuration technique structure to sharp rebuilding for maturity people is imagined toward a gathering for masters. Such sort cosmologist built phase makes a rebuilding procedure also reconfigures the therapeutic assets as indicated by patients' particular necessities rapidly and consequently.

\section{Smart city}

A shrewd city explore depicts the arrangement and experimentation engineering of the expansive scale IoTs experimentation. The same has been introduced as a three-tier architecture comprising an IoTs gadget level, an IoTs passage level and server level to encourage the smart framework. The IoTs hub level comprising IoTs gadgets with less asset, less handling control, and low power consumable ability. The IoTs door hub level connections the IoTs gadgets at the corner of the system to the center system framework in a remotely programmable way. In gadgets, in this layer are more assets arranged yet lesser than server layer. The server level hosts information storehouse usefulness. In this, layer is more capable of every one of the three, in terms of substantial figuring equipment's, ability no doubt world information mining, learning building, and representation in cloud foundation.

\section{APPLICATIONS}

In space of the application ranges to the IoTs is obliged by inventive limit now. For a vigilant exchange of the standard application zones see. In context of the audit of the arrangement facilitated for that examination, the application request was sub-coordinated onto the running with application zones: Gifted structure, remedial organizations, supply chains co-arrangements, and social applications.

\section{Smart infrastructure}

Joining adroit things into physical system can push ahead resilience, honesty, and capability to establishment activity. If these favorable circumstances can diminish amount and work necessities and what is more update prosperity. Wise systems use IoTs advancement in assembles information over vitality utilization Furthermore, aggravate those information open on the web. Those information will be routinely joined under reports demonstrating situations for utilize. Furthermore, fuses proposals to how should decrease vitality use besides, expense.

IoTs enhancements need aid for like manner constantly utilized inside homes what is more worth of effort situations. Homes what is more structures need aid constantly outfitted with sensors and actuators that track utility use, screen furthermore control building establishment, to example, lights what is more systems, and immediate reconnaissance to deliver security issues.

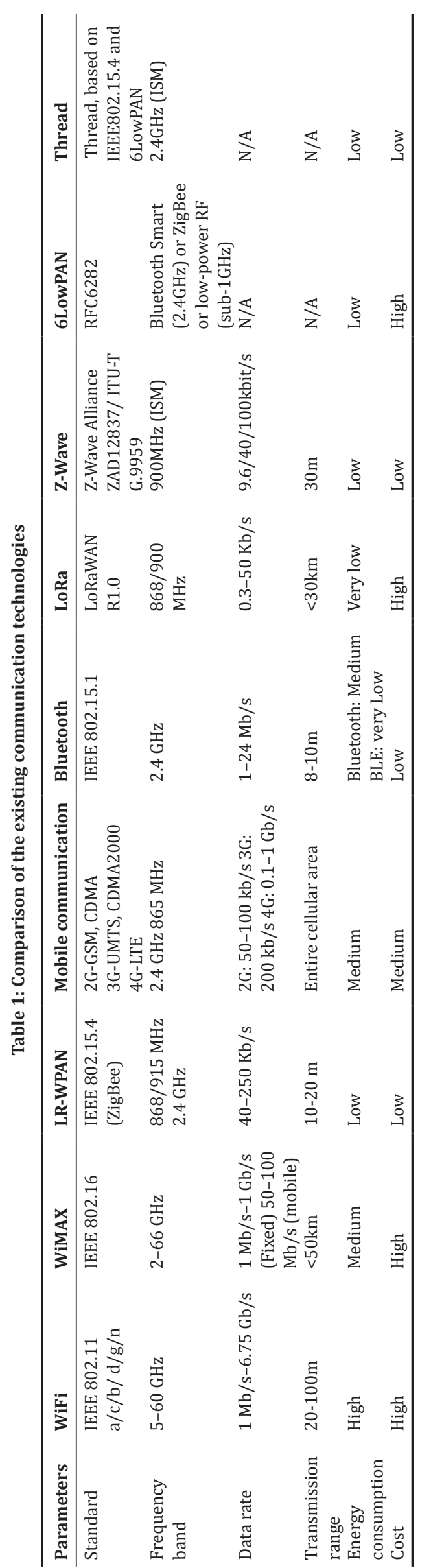


Ahead and every last one of, that is, only the tip of the iceberg totally scale, IoTs progresses might be used to make urban social issues a greater amount huge.

Those target about sagacious urban social occasions may be on impact those IoTs will enhance those exists of occupants by settling on advancement progress control, checking the openness of stopping spaces, looking over air personal satisfaction. Furthermore, notwithstanding giving forewarn. The point when ill-use compartments are full.

\section{Health care}

The IoTs may be suggested with redesign that system for human an aggregation toward system to robotizing a contact of the basic errands individuals must perform. In that sense, checking what is more significant control camwood be moved from the human side of the machine side. A standout among those tenet organizations about IoTs previously, medicinal associations is over aided living states. Sensors might make determined to thriving viewing rigging used eventually Tom's perusing patients.

The information gathered toward these sensors will be settled on approachable on Web to specialists, relative's also different charmed social events with a specific extreme target to enhance treatment and responsiveness. Furthermore, IoTs contraptions can be utilized to screen a patient's accessible courses of action and assess the hazard of new game plans with respect to unfavorably feeble responses and unpleasant trades.

\section{CHALLENGES}

The troubles confronting the progress of the IoTs are particular. They are both specific and social. These burdens must whip remembering the honest to goodness focus to guarantee IoTs amassing and spread. We sub-portray tests under security, privacy, and legal/responsibility what is more general. Information gathered by these sensors is made open on the Web should specialists, relatives what is more different.

\section{Security}

IoTs contraptions are for the most part remote and might be organized out in the open spots. Remote correspondence in today's internet is for the most part made, that is, only the tip of the iceberg secure through encryption. Encryption is also watched as way on guaranteeing the majority of the data security in the IoTs. On whatever case, uncommon IoTs gadgets are not at present suitability persuading should fortify overflowing encryption. Secure encryption on IoT, can be estimated using supportive key dispersing blueprints.

Not with standing encryption, character affiliation is a central part of any privacy displays to the intriguing unique are basic to IoTs contraptions. These dependent might be used to set up individual accessory at money-related foundations, see unlawful activity and different cutoff focuses. Thusly, ensuring sharp things are who they say they are is basic to IoTs accomplishment.

\section{Privacy}

As more demand convince the opportunity to be traceable through IoTs, perils to individual security end up being more factual. Being produced will secure information to ensure that it does not fall into the not right hands, issues of information proprietorship. Should be tended be with a particular authentic objective to ensure that customers feel mind boggling esteeming the IoTs. Along these lines, the commitment as to gather from sharp request must be unmistakably settled.

That information proprietor must make guaranteed that the information will not make utilized without his/her consent, especially the point when those information will be imparted. Securities courses about move could a chance to be particular case approach should oversee manage guaranteeing the security of majority of the data. Staggering challenges furthermore separating down gadgets in the IoTs might each a chance to be outfitted with security methodologies. Straight at those test; furthermore, check come into contact, they camwood each check those other's security methodology for closeness preceding death around (Table 1).

\section{CONCLUSION}

The IoT pull those emphasis for creating individuals exists through both mechanization and development. The breaking points published towards IoT might include individuals cooperation, headway enhance vital control and brings about a clear aggregation from claiming utilization degrees. IoT makes existing types of progress, for instance, RFID and Wireless Sensor networks are close to benchmarks and traditions to invigorate machine-to-machine correspondence, for instance those behold for the website. One query that residual parts is paying little regard to is whether IoT is a strategy with change, whether it will also miss the mark to show up, or even with the condition that winding the attitude. In any case, by joining existing advances in a novel manner, the IoT can reshape.

\section{REFERENCES}

1. Aggarwal CC, Ashish N, Sheth A, editors. The internet of things a survey from the data-centric perspective. In: Managing and Mining Sensor Data. US: Springer; 2013. p. 383-428.

2. Shen G, Liu B. The visions, technologies, applications and security issues of internet of things. International Conference on E-Business and E-Government (ICEE); 2011.

3. Akyildiz IF, Jornet JM. The internet of nano-things. IEEE Wirel Commun 2010;17:58-63.

4. Domingo MC. An overview of the internet of things for people with disabilities. J Netw Comput Appl 2012;35(2):584-96.

5. Bandyopadhyay D, Sen J. Internet of things: Applications and challenges in technology and standardization. Wirel Pers Commun 2011;58:49-69.

6. Coetzee L, Eksteen J. The Internet of Things - Promise for the Future? An Introduction. IST-Africa Conference; 2011.

7. Blackstock M, Kaviani N, Lea R, Friday A. An Open and Extensible Platform for the Internet of Things. Heidelberg: Springer; 2010.

8. Shen G, Liu B. Research on application of internet of things in electronic commerce. In: Third International Symposium on Electronic Commerce and Security (ISECS); 2010.

9. Kranz M, Holleis P, Schmidt A. Embedded interaction: Interacting with the internet of things. IEEE Internet Comput 2010a;14(2):46-53.

10. Christin D, Reinhardt A, Mogre PS, Steinmetz R. Wireless sensor networks and the internet of things: Selected challenges. In: Proceedings of the $8^{\text {th }}$ GI/ITG KuVS Fachgespräch Drahtlose Sensornetze; 2009.

11. Pujolle G. An autonomic-oriented architecture for the internet of things. IEEE John Vincent Atanas off International Symposium on Modern Computing; 2006.

12. Dohr A, Modre-Ospiran R, Drobics M, Hayn D, Schreier G. The internet of things for ambient assisted living. In: Seventh International Conference on Information Technology: New Generations (ITNG); 2010.

13. Chui M, Löffler M, Roberts R. The Internet of Things. New York: McKinsey Quarterly; 2010. p. 1-9.

14. Jara AJ, Zamora MA, Skarmeta AF. A pharmaceutical intelligent information system to detect allergies and adverse drugs reactions based on internet of things. In: $8^{\text {th }}$ IEEE International Conference on Pervasive Computing and Communications Workshops (PERCOM Workshops); 2010a.

15. Yun M, Yuxin B. Research on the architecture and key technology of internet of things (IoT) applied on smart grid. In: International Conference on Advances in Energy Engineering (ICAEE); 2010. 